\title{
Involvement of ROS and JNK1 in selenite-induced apoptosis in Chang liver cells
}

\author{
Yong-sook Kim ${ }^{1}$, Deok-young Jhon ${ }^{1}$ \\ and Kee-Young Lee Le $^{2,3}$ \\ ${ }^{1}$ Department of Food and Nutrition \\ College of Human Ecology \\ Chonnam National University \\ Gwangju 500-757, Korea \\ ${ }^{2}$ Department of Biochemistry \\ College of Medical School, Chonnam National University \\ Chonnam National University Research Institute of Medical Sciences \\ Gwangju 501-190, Korea \\ ${ }^{3}$ Corresponding author: Tel, 82-62-220-4103; \\ Fax, 82-62-227-8321; E-mail, kylee@jnu.ac.kr \\ Accepted 10 February 2004
}

Abbreviations: JNK1, c-jun N-terminal kinase1; ERK, extracellular signal-regulated kinase; ROS, reactive oxygen species

\begin{abstract}
Selenium is a dietary essential trace nutrient with important biological roles. Selenocompounds were reported to induce apoptosis in many types of tumor cells. In this study, we investigated the signaling pathway involved in the selenite-induced apoptosis using Chang liver cells as a non-malignant cell model. The Chang liver cell apoptosis induced by selenite $(10 \mu \mathrm{M})$ was confirmed by DNA fragmentation and typical apoptotic nuclear changes. Treatment of selenite increased intracellular reactive oxygen species (ROS) level and c-Jun $\mathrm{N}$-terminal kinase1 (JNK1) phosphorylation. The selenite-induced cell death was attenuated by SP600125, a specific inhibitor of JNK, and by dominant negative JNK1 (DN-JNK1). Antioxidants such as glutathione (GSH), $\mathrm{N}$-acetyl cysteine (NAC), curcumin, epigallocatechin gallate (EGCG) and epicatechin (EC) inhibited selenite-induced intracellular ROS elevation and JNK1 phosphorylation. Our results suggest that selenite-induced apoptosis in Chang liver cells was preceded by the ROS generation and JNK1 activation.
\end{abstract}

Keywords: apoptosis; Chang liver cell; JNK1; ROS; selenite

\section{Introduction}

Selenium is a dietary essential trace element with important physiological functions and known to incorporate into proteins in the form of selenocysteine involved in functions of several enzymes and proteins such as glutathione peroxidases, selenoprotein $P$ and thioredoxin reductases (Stadtman, 1991). Most of the selenoproteins have reactive oxygen species (ROS) scavenging activities, so that the action of selenium has been known as an antioxidation system in cell survival. In these aspects, selenium is recommended for nutritional additive in sustaining a long healthy life.

On the other hand, accumulating evidences indicate that seleno-compounds possess the anticancer properties (Clark et al., 1996; Combs and Gray, 1998). The anticancer effects were suggested to be an inhibitory action on cell proliferation in various tumor cells. In addition, selenite is known to induce apoptosis in many malignant cells such as hepatoma, prostate cancer, lung cancer and gastric cancer cell lines (El-Bayoumy, 2001; Gasparian et al., 2002). The cytotoxic activity of selenite is suggested to be associated with the oxidative stress (Shen et al., 2001) and interaction with thiol groups in proteins (Frost and Lish, 1975). The type of cytotoxicity was reflected closely with apoptosis of various tumor cell lines (Shen et al., 2001; Jiang et al., 2002), and the underlying apoptotic signaling pathway is widely investigated. Others, however, proposed that selenite-induced cell death could be derived from necrosis rather than apoptosis (Kim et al., 2001; Zeng, 2001). Taken together, the anticancer effect of selenite was suggested to be an inducer of cell death.

ROS was reported to correlate with apoptosis in many cells, and the pathway of ROS-mediated apoptosis was suggested. Several studies have reported that intracellular ROS level was increased by selenite, and the mechanisms underlying ROS production was inferred to be related with selenite. Sheng et al. (2001) reported that superoxide radical initiated apoptosis in HepG2 cells, and Mates and SanchezJimenez (2000) reviewed about the implications of ROS in apoptosis. On the other hand, Sakon et al. (2003) indicated that ROS induced by tumor necrosis factor (TNF) mediated necrotic cell death. Seleniteinduced cell death might be contributed by oxidative cytotoxicity. Recent studies have shown that both endogenously produced and exogenously added ROS can regulate the activity of mitogen-activated protein 
kinases (MAPKs) pathways that may be involved in cellular responses including proliferation, differentiation and apoptosis (Sano et al., 2001; Jang et al., 2002). MAPKs include three major kinases; extracellular signal-regulated kinase (ERK), p38 kinase and c-Jun N-terminal kinase (JNK). These kinases have a number of isoforms generated by alternative splicing of the pre-mRNA. ERK is generally activated by $\mathrm{mi}-$ togenic and proliferative stimuli such as growth factors and involved in cellular proliferation and differentiation. JNK and p38 kinase are mainly activated by extracellular stresses, such as UV irradiation, inflammatory cytokines, heat and arsenic trioxide (Kyriakis and Avruch, 2001; Chung et al., 2003; Kang et al., 2003). Activation of these protein kinases causes variable cellular responses depending on the cell type. JNK is believed to be regarded as signaling pathways for apoptosis, transformation, development, immune activation, inflammation and adaptation to environmental changes (Davis, 2000). JNK1 activation by cytotoxic agents was reported that its activation is mediated by oxidative or mechanical stress in the form of ROS or microtubule perturbations, respectively ( $\mathrm{Yu}$ et al., 1996; Shtil et al., 1999). In addition, Ham et al. (2003) reported that JNK1 is up-regulated in apoptotic cells induced by gensenoside Rh2, a ginseng saponin.

In the present study, we investigated that seleniteinduced death mechanism of the Chang liver cells as the non-malignant cell model involving ROS and JNK. This study shows that JNK1 activation in Chang liver cells treated with selenite is associated with apoptotic pathway mediated by elevation of intracellular ROS level.

\section{Materials and Methods}

\section{Chemicals}

Dulbecho's modified essential media (DMEM), fetal bovine serum (FBS) and antibiotics (penicillin, streptomycin and amphotericin) were purchased from Gibco BRL (Grand island, NY). Apparatuses for cell culture were purchased from Nunc (Rochester, NY). Propidium iodide $(\mathrm{PI})$, sodium selenite, reduced glutathione (GSH), N-acetyl-L-cysteine (NAC), (-)-epigallocatechin-3-gallate (EGCG), (-)-epicatechin (EC), ascorbate, a-tocopherol, curcumin, 2,7-dichlorofluorescindiacetate (DCFH-DA), and C,N-diphenyl-N-4,5-dimethyl thiazol-2-yl tetrazolium bromide (MTT) were purchased from Sigma (St. Louis, MO). SP600125 was from Calbiochem (Darmstadt, Germany). Rabbit anti-phospho-MKK4, -JNK1, -ERK and -p38 antibodies were purchased from Cell Signaling Technology (Beverly, MA) and monoclonal anti-actin antibody was from Sigma. Calcium phosphate transfection kit was purchased from Invitrogen (Carlsbad, CA).

\section{Cell culture}

Chang liver cell was cultured in DMEM containing 100 $\mathrm{U} / \mathrm{ml}$ penicillin, $0.1 \mathrm{mg} / \mathrm{ml}$ streptomycin, $0.25 \mu \mathrm{g} / \mathrm{ml}$ amphotericin, and $10 \%$ heat-inactivated FBS. Cells were incubated at $37^{\circ} \mathrm{C}$ in the humidified atmosphere of $95 \%$ air and $5 \% \quad \mathrm{CO}_{2}$.

\section{MTT assay}

The viability of Chang liver cells was determined by MTT assay. Cells were cultured in 96 well microplate at a density of $2 \times 10^{3}$ cells per well. After incubation with reagents for $24 \mathrm{~h}$, the media were replaced with MTT solution $(5 \mathrm{mg} / \mathrm{ml})$. Incubation was further continued for $2 \mathrm{~h}$, and then supernatant was removed by aspiration. Then, dimethyl sulfoxide (DMSO) was added and the absorbance was read at $570 \mathrm{~nm}$ on microplate reader (Molecular Devices), and the percentage of cell viability was obtained.

\section{DNA isolation}

Control or treated cells were collected by centrifugation, and washed in cold phosphate-buffered saline (PBS). Pellets were then suspended in lysis buffer containing $0.2 \%$ Triton $\mathrm{X}-100,10 \mathrm{mM}$ EDTA and 10 $\mathrm{mM}$ Tris ( $\mathrm{pH}$ 7.5). After centrifugation for $20 \mathrm{~min}$ at $12,000 \mathrm{~g}$, the supernatants were collected and incubated with $200 \mu \mathrm{g} / \mathrm{ml}$ proteinase $\mathrm{K}$ for $3 \mathrm{~h}$ at $50^{\circ} \mathrm{C}$ in the presence of $1 \% \operatorname{SDS}(\mathrm{w} / \mathrm{v})$. Then the incubation with RNase A $(200 \mu \mathrm{g} / \mathrm{ml})$ at $37^{\circ} \mathrm{C}$ was followed for at least $3 \mathrm{~h}$. DNA fragments were precipitated with 2.5 volumes of ethanol in the presence of 0.1 volume of $3 \mathrm{M}$ sodium acetate at $-20^{\circ} \mathrm{C}$ overnight. After centrifugation, samples were washed with $70 \%$ ethanol and resuspended in buffer containing $1 \mathrm{mM}$ EDTA and 10 $\mathrm{mM}$ Tris $\mathrm{pH}$ 7.4. Gel-loading dye was added to the samples and horizontal electrophoresis was performed in $0.5 \times$ TBE buffer ( $45 \mathrm{mM}$ Tris/borate, $1 \mathrm{mM}$ EDTA) on $1.8 \%$ agarose gels containing ethidium bromide.

\section{Detection and Quantification of Apoptotic Nuclei}

For nuclei staining, cells were fixed with $70 \%$ ethanol for $10 \mathrm{~min}$, rinsed three times with PBS, and stained with propidium iodide $(1 \mu \mathrm{g} / \mathrm{ml})$ in PBS for $10 \mathrm{~min}$. The slides were observed with a conventional light and fluorescence microscope.

\section{Measurement of ROS generation}

DCFH-DA is a non-polar compound which enters the cell and is cleaved to form DCFH. Trapped DCFH is oxidized by oxygen free radicals to produce fluorescent DCF. Chang liver cells were cultured on 96 well microplate to $2 \times 10^{3}$ cell per well. The cells were preincubated for $1 \mathrm{~h}$ at $37^{\circ} \mathrm{C}$ in the presence of 10 
$\mu \mathrm{M}$ DCFH-DA and the cells were incubated with selenite in the presence or absence of numerous reagents. Fluorescence intensity was analyzed by fluorospectroscan (Fluoroscan Ascent FL, Labsystems) using $485 \mathrm{~nm}$ excitation and $538 \mathrm{~nm}$ emission filter.

\section{Westernblot analysis}

Chang liver cells were harvested by centrifugation and washed with cold PBS. Cells were lysed in lysis buffer (50 mM Tris pH 8.0, $150 \mathrm{mM}$ EDTA, 1\% Triton X-100, $1 \mathrm{mM}$ PMSF, $1 \mu \mathrm{g} / \mathrm{ml}$ leupeptin, $1 \mathrm{mM}$ dithiothreitol (DTT)) and kept on ice for $30 \mathrm{~min}$, followed by centrifugation at $10,000 \mathrm{~g}$ for $10 \mathrm{~min}$ at $4^{\circ} \mathrm{C}$. The supernatant was collected and protein content was determined by using Bradford reagent (BioRad Laboratories, Hercules, CA). Protein sample was mixed with $2 \times$ loading buffer $(125 \mathrm{mM}$ Tris $\mathrm{pH} \mathrm{6.8,4 \%} \mathrm{SDS,}$ $10 \%$ glycerol, $0.006 \%$ bromophenol blue, $1.8 \%$ betamercaptoethanol) and separated by electrophoresis on $10 \%$ SDS-polyacrylamide gel. The protein $(50 \mu \mathrm{g})$ was electrophoretically transferred onto nitrocellulose membrane (Amersham Life Science, Bucks, UK). The membrane was blocked in $5 \%$ skim milk for $1 \mathrm{~h}$ at room temperature, then incubated with primary antibody against phosphorylated JNK1, -p38 kinase or -ERK. After incubation, membrane was washed with TTBS $(100 \mathrm{mM}$ Tris $\mathrm{pH} 7.5,0.9 \% \mathrm{NaCl}, 0.1 \%$ Tween 20) for three times, then incubated with Horseradishperoxide-conjugated secondary antibody for $1 \mathrm{~h}$ and washed with TTBS for three times. The blots were detected by enhanced chemiluminescence (ECL) as recommended by manufacturer (iNtRON, Seoul, Korea).

\section{Establishment of stable cell lines}

Plasmid pcDNA3, pcDNA3-Flag-JNK1 and pcDNA3Flag-DN-JNK1 were kindly provided by Dr. S. K. Lee (Seoul National University). Chang liver cells were transfected with pcDNA3, pcDNA3-Flag-JNK1, or pcDNA3-Flag-DN-JNK1 using the calcium phosphate transfection kit (Invitrogen, CA), according to the manufacturer's protocol. Transfected cells were grown in culture media containing $600 \mathrm{mg} / \mathrm{ml} \mathrm{G} 418$ for 2 weeks. Surviving clones expressing JNK1 and DNJNK1 were selected and used for experimental procedures.

\section{Statistical analysis}

All data were expressed as mean \pm S.D. and evaluated by using the student's t-test with SPSS software. Data were considered as statistically significant when $P$ value was less than 0.05 .

\section{Results}

Sodium selenite induced the elevation of ROS level and apoptosis

The cytotoxic effect of selenite was measured by MTT assay. Cells were exposed to various concentrations of selenite for $24 \mathrm{~h}$ and viability was assayed.
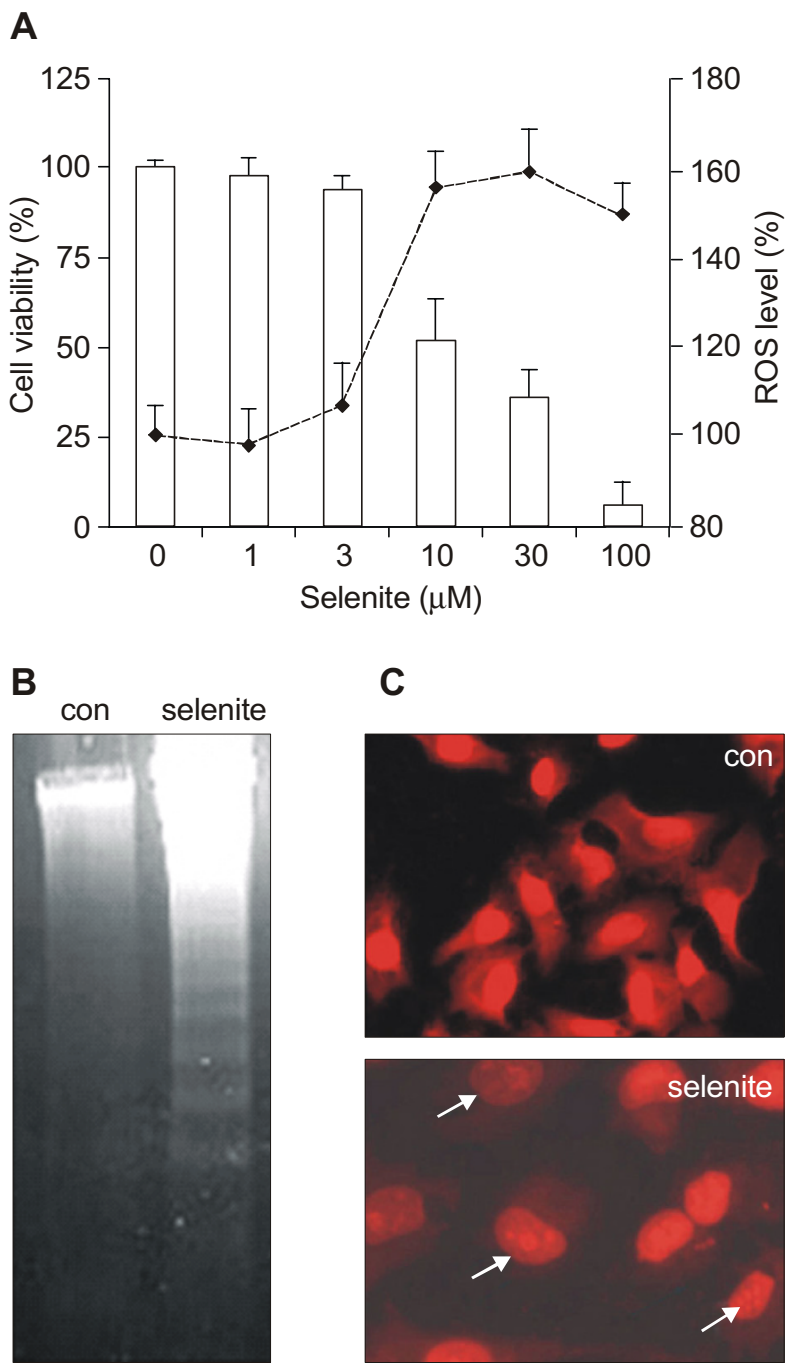

C
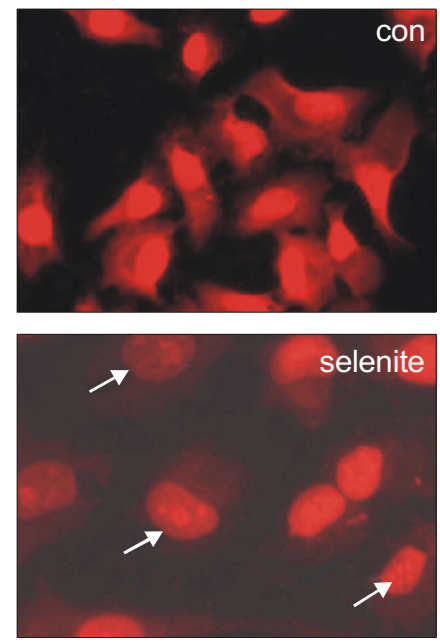

Figure 1. Selenite induced apoptosis in Chang liver cells. (A) Chang liver cells were incubated with various concentrations of sodium selenite for $24 \mathrm{~h}$ and cytotoxicity was measured by MTT assay as described in Materials and Methods. The results are expressed as relative viabilities (\%) from the OD570 values. Cells were incubated with indicated concentrations of selenite for $1 \mathrm{~h}$ and intracellular ROS level was measured. Each bar represents the mean \pm S.D. *indicates the significantly effective concentration of selenite $(P<0.05)$. (B) Cells were incubated with selenite $10 \mu \mathrm{M}$ for $24 \mathrm{~h}$ and isolated DNA was separated on $1.8 \%$ agarose gel electrophoresis. (C) Cells were incubated with selenite $10 \mu \mathrm{M}$ for $24 \mathrm{~h}$ and stained with PI. Nuclear piknosis (arrows) were observed in selenite treated cells under fluorescent microscopy. 
Selenite below $3 \mu \mathrm{M}$ showed no cytotoxicity, however, $10 \mu \mathrm{M}$ or greater levels of selenite began to show cytotoxic effect in a concentration dependent manner (Figure 1A). To identify the type of cell death, DNA fragmentation and nuclear characteristics were investigated. The ladder pattern of DNA fragmentation was shown in selenite-treated cells (Figure 1B). In PI staining, the nuclear piknosis was observed in selenite treated cells (Figure 1C). To examine whether the selenite-induced apoptosis is mediated by oxidative stress, the intracellular level of ROS measured. DCFH-DA was used to detect the level of intracellular ROS by selenite. Cells were treated with various concentrations of selenite for $1 \mathrm{~h}$ and intracellular ROS was measured (Figure 1A). ROS was increased to $150 \%$ by $10 \mu \mathrm{M}$ selenite in $5 \mathrm{~min}$ and sustained for $2 \mathrm{~h}$ (data not shown).

\section{MAPKs phosphorylation during selenite treatment}

To examine whether MAPKs are activated during selenite treatment, the phosphorylations of MAPKs were measured by Western-blot using anti-phosphorylated antibodies. JNK1 phosphorylation was increased at $30 \mathrm{~min}$ after selenite $(10 \mu \mathrm{M})$ treatment and sustained for $2 \mathrm{~h}$, and gradually decreased to the basal level at $24 \mathrm{~h}$. The degree of ERK phospho was not changed during selenite treatment while p38 kinase phosphorylation increased slightly (Figure 2).

\section{Inhibition of JNK activity by dominant negative JNK1 or SP600125}

To determine whether the activation of JNK1 contributes to selenite-induced apoptosis, we assessed whether the inhibition of JNK1 activity might affect the viability of selenite-treated cells. JNK1 activity was inhibited by stably transfecting Chang liver cells with

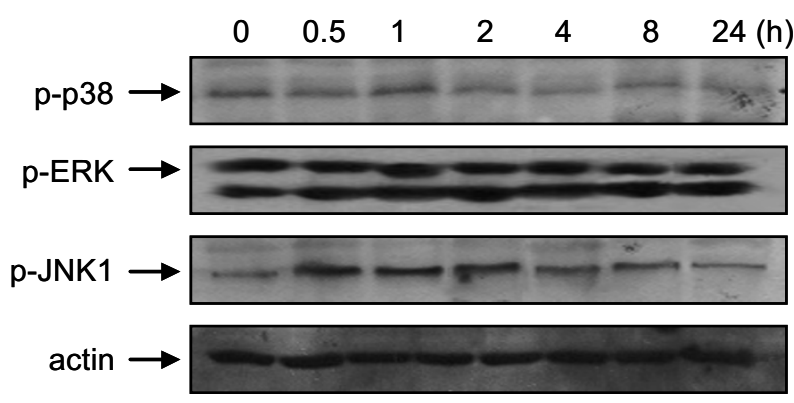

Figure 2. Effects of selenite on MAPKs phosphorylation. Chang liver cells were treated with selenite $10 \mu \mathrm{M}$ for indicated time and cell extracts $(50 \mu \mathrm{g})$ were subjected to Westernoblot analysis with p-p38, p-ERK or p-JPK1 antibody. Phosphorylations of these kinases were visualized by ECL as described in manufacturer's protocol. dominant negative JNK1 (DN-JNK1). Cells transfected with the empty vector construct (mock), with JNK1, or with dominant negative JNK1-expressing cells and untransfected control cells were treated with selenite for $24 \mathrm{~h}$. In the vector transfectants (mock), selenite treatment reduced cell viability to $40 \%$ as in the wild type cells (Figure $3 \mathrm{~A}$ ). This cytotoxic effect of selenite was enhanced in the JNK1 transfectants (18.5\%). On the other hand, selenite-induced cytotoxicity was markedly attenuated in the DN-JNK1 transfectants $(58.9 \%)$.

To determine the effect of SP600125 on seleniteinduced dell death, the cells were preincubated with SP600125 $(0,3,10,30 \mu \mathrm{M})$ for $30 \mathrm{~min}$ and then treated with selenite $(10 \mu \mathrm{M})$ for $24 \mathrm{~h}$. Cell viability

A

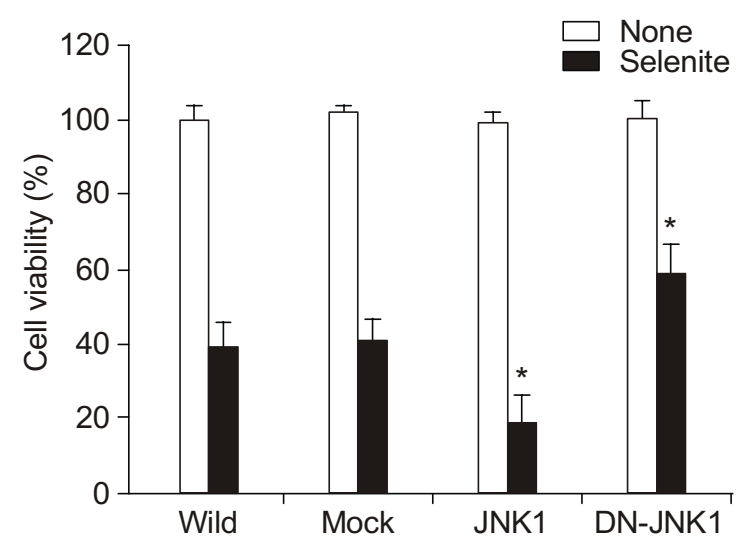

B

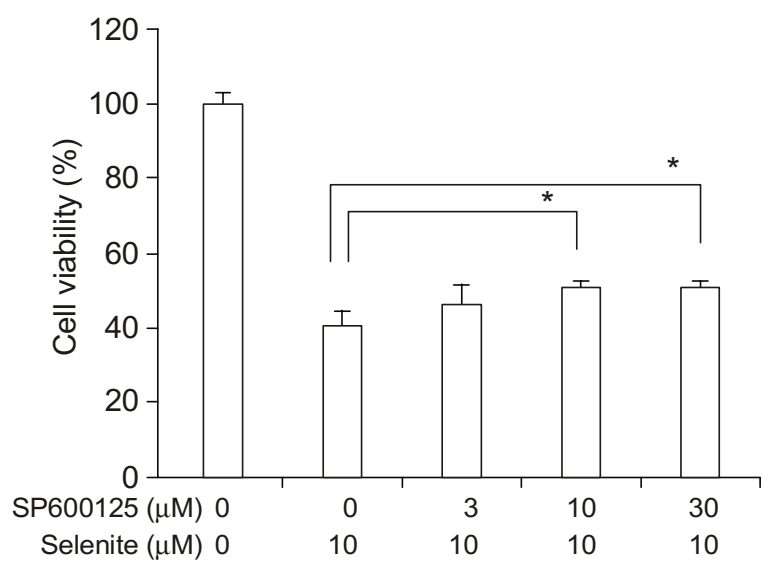

Figure 3. Effects of JNK1 inhibition by DN-JNK1 transfection or SP600125 on selenite-induced cell death. (A) Cells were stably transfected with empty vector pcDNA3 (mock), pcDNA3-JNK1 or pcDNA3DN-JNK1. Untrasnfected cells (wild) and transfectants were incubated with $10 \mu \mathrm{M}$ selenite for $24 \mathrm{~h}$, and MTT assay was performed to check the cell viability. (B) Cells were pretreated with SP600125 for $30 \mathrm{~min}$ prior to selenite treatment. After $24 \mathrm{~h}$, cell viability was measured. Each bar represents mean \pm S.D. ${ }^{*}<$ 0.05 vs. selenite treatment. 
A

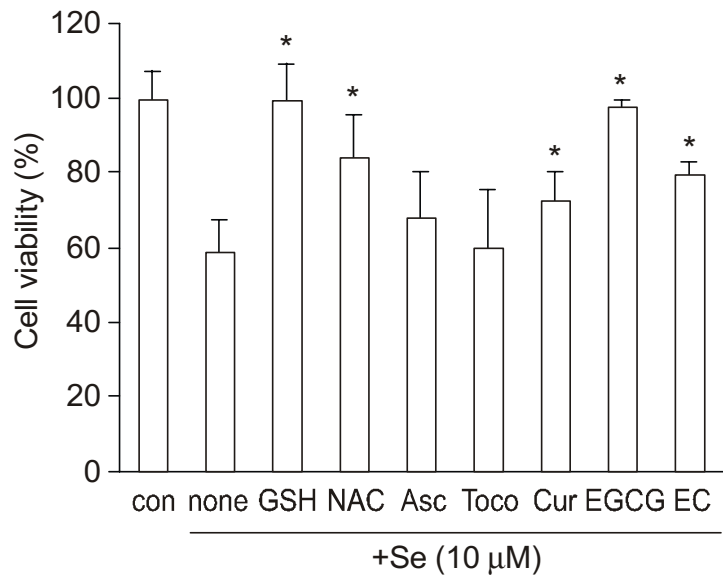

B

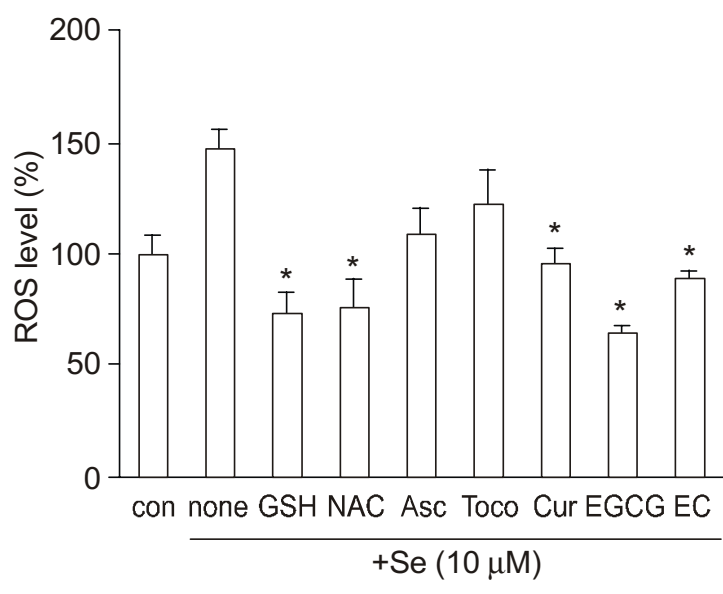

C

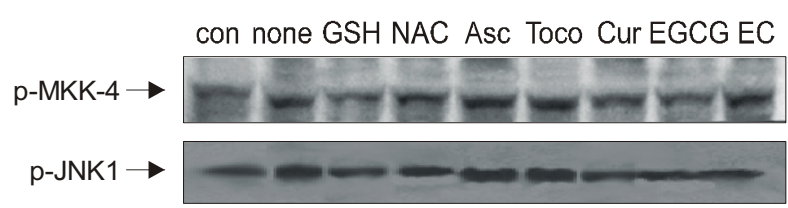

Figure 4. A, Effects of antioxidants on selenite-induced cell death. (A) Cells were incubated with GSH $(10 \mathrm{mM}), \mathrm{NAC}(20 \mathrm{mM})$, ascorbate $(100 \mu \mathrm{M}), \alpha$-tocopherol $(100 \mu \mathrm{M})$, curcumin $(20 \mu \mathrm{M})$, EGCG $(20 \mu \mathrm{M})$ and EC $(100 \mu \mathrm{M})$ in the presence of selenite $(10 \mu \mathrm{M})$. Followed by incubation for $24 \mathrm{~h}$, cell viability was measured by MTT assay as described in Materials and Methods. (B) Cells were incubated with $\mathrm{GSH}(10 \mathrm{mM}), \mathrm{NAC}(20 \mathrm{mM})$, ascorbate $(100 \mu \mathrm{M}), \alpha$-tocopherol $(100 \mu \mathrm{M})$, curcumin $(20 \mu \mathrm{M})$, EGCG $(20 \mu \mathrm{M})$ and EC $(100 \mu \mathrm{M})$ in the presence of selenite $(10 \mu \mathrm{M})$. Followed by incubation for $1 \mathrm{~h}$, generation of ROS was determined by using DCFH-DA as described in Materials and Methods. Each bar represents mean \pm S.D. ${ }^{*}<0.05$ vs. selenite treatment. (C) Cells were incubated with antioxidants with selenite $10 \mu \mathrm{M}$ for $30 \mathrm{~min}$. GSH $(10 \mathrm{mM})$, NAC $(20 \mathrm{mM})$, ascorbate $(100 \mu \mathrm{M}), \alpha$-tocopherol $(100 \mu \mathrm{M})$, curcumin $(20 \mu \mathrm{M})$, EGCG $(20$ $\mu \mathrm{M})$ and $E C(100 \mu \mathrm{M})$ in the presence of selenite $(10 \mu \mathrm{M})$. Followed by incubation for $30 \mathrm{~min}$, immunoblots (protein $50 \mu \mathrm{g}$ ) were performed by using anti-phosphorylated MKK4 and JNK1 antibody as described in Materials and Methods. Se, selenite; NAC, N-acetyl cysteine; Asc, ascorbate; Toco, a-tocopherol; Cur, curcumin; EC, epicatechin. was partially recovered in the presence of SP600125 compared to in selenite alone treated cells with statistical significance $(50.6 \%$ at $10 \mu \mathrm{M}$ and $51 \%$ at $30 \mu \mathrm{M}$, respectively vs. $41 \%$ in selenite alone treated cells).

\section{Selenite-induced JNK1 phosphorylation and cytotoxicity were reduced by blocking of intracellular ROS}

To confirm whether the intracellular ROS serves selenite-induced cytotoxicity, the effects of antioxidants were examined on cell death and intracellular ROS level. Cells were pre-treated with GSH $(10 \mathrm{mM}), \mathrm{NAC}$ $(20 \mathrm{mM})$, ascorbate $(100 \mu \mathrm{M})$, $\alpha$-tocopherol $(100 \mu \mathrm{M})$, curcumin $(20 \mu \mathrm{M})$, EGCG $(20 \mu \mathrm{M})$ or EC $(100 \mu \mathrm{M})$ for $30 \mathrm{~min}$, and then treated with selenite $(10 \mu \mathrm{M})$ for $24 \mathrm{~h}$, followed by MTT assay. The working concentrations of the antioxidants described above did not affect the cell viability and intracellular ROS level (data not shown). As seen in Figure 4A, cell death induced by selenite was significantly decreased by GSH, NAC, curcumin, EGCG and EC. In cases of GSH and EGCG, the treated cells recovered cell viability almost $100 \%$. NAC, curcumin and EC also significantly protected selenite-induced cell death, whereas, ascorbate and a-tocopherol caused no significant changes in death rate induced by selenite treatment. Figure 4B showed that GSH, NAC, curcumin, EGCG and EC inhibited the increase of DCF fluorescence in the cells treated with selenite $(10 \mu \mathrm{M})$. On the other hand, ascorbate and $\alpha$-tocopherol did not inhibit the ROS elevation significantly.

To examine whether the antioxidants reduce the selenite-induced phosphorylation of JNK1, cells were pretreated with antioxidants for $30 \mathrm{~min}$ prior to selenite treatment and JNK1 phosphorylation was compared with MKK4 phosphorylation. MKK4 phosphorylation was increased by selenite treatment and consequencially JNK1 phosphorylation was also increased. This result suggested that JNK1 activation is linked to the MKK4-mediated mechanism. The selenite-induced phosphorylation of MKK4 and JNK1 was reduced by GSH, NAC, curcumin, EGCG and EC whereas was not changed by ascorbate and $\alpha$-tocopherol (Figure 4C).

\section{Discussion}

The results presented in this work agree with those earlier reports in a notion that sodium selenite causes apoptosis, and the toxicity of selenite is mediated by increase of intracellular ROS. Earlier reports of selenite induced the apoptosis in various tumor cells showed that $10 \mu \mathrm{M}$ of selenite exerted the chemo- 
therapeutic effect by inducing apoptosis in tumor cells in $24 \mathrm{~h}$ (Shen et al., 2001; Jiang et al., 2002). Our observation that $10 \mu \mathrm{M}$ selenite also lead to nonmalignant cell, Chang liver cells, to apoptotic death in $24 \mathrm{~h}$ (Figure 1) may present entirely different selenite effects based on dose-related cytotoxicity. The dual effects of selenite in cells, either as a pro-oxidant as seen in our data, or as an anti-oxidant, are still not clear.

We confirmed selenite-induced apoptosis in Chang liver cells by showing form of DNA fragmentation ladder and characteristics of nucleus. Apoptosis is induced by various physiological factors and stimuli such as cytokines, Fas ligand and ROS. Intracellular ROS was also increased in selenite treatment as shown in Figure 1A. Shen et al. (2000) reported that selenite was able to deplete the intracellular GSH concentration and induced ROS formation in HepG2 cells. Several reports suggested that selenite induced mitochondrial membrane potential loss which is mediated through the opening of permeability transition pore (Shen et al., 2001; Zhu et al., 2002). Kim et al. (2002) suggested that selenite directly modified protein thiol groups resulting in the mitochondrial permeability transition, and a loss of mitochondrial membrane potential.

One of the important affector of ROS is mitogenactivated protein kinases (MAPKs) including JNK, p38 kinase and ERK. JNK, also known as stressactivated protein kinase (SAPK), has three isoforms JNK1, JNK2 and JNK3. In general, JNK is activated by cellular stress and plays numerous roles in various cellular functions. Whether selenite affects JNK activation still remains controversial. In the cells pretreated with selenite $(100 \mathrm{nM})$ for $48 \mathrm{~h}$, UV-induced JNK1 activation was inhibited likely via a thiol redox mechanism (Park et al., 2000). Pretreatment of cells with selenite $(2 \mu \mathrm{M})$ for $12 \mathrm{~h}$ inhibited the apoptosis induced by hydrogen peroxide $(500 \mu \mathrm{M}, 15 \mathrm{~min})$ in HT1080 (Yoon et al., 2002). They proposed that selenite exerts the effect by inhibition of ASK1 and JNK via the PI3-K-dependent pathway (Yoon et al., 2002). On the other hand, Nango et al. (2003) demonstrated that selenite induced the apoptosis through the activation of JNK in regenerating rat liver cells. In addition, recent studies showed that ROS could activate the MAPKs. $\beta$-Amyloid caused the production of ROS and subsequent JNK activation (Jang and Surh, 2002), and ROS induced the phosphorylation of JNK, ERK and p38 kinases (Sano et al., 2001; Lee and Esselman, 2002). These results indicated that selenite induced intracellular ROS production, and consequential activation of JNK might play a role in apoptosis induction. Since JNK1 was phosphorylated by selenite as described in our results, we investigated whether JNK1 inhibition affects on selenite-induced cell death. To block the activation of JNK1, we used DN-JNK1, a dominant negative form of JNK1, and SP600125, a specific inhibitor of JNK. The results showed overexpression of DN-JNK1 efficiently reduced the selenite-induced cell death. But SP600125 exerted its inhibitory effect on seleniteinduced cell death but not as efficiently as in DNJNK1 (Figure 3A, B). From these data, it is evident that JNK1 activation plays an important role in selenite-induced apoptosis.

As ROS have been reported to play important roles in apoptosis (Rhee, 1999), selenite would induce the apoptosis may occur through intracellular ROS generation and antioxidants may attenuate the seleniteinduced apoptosis. Among various antioxidants, GSH and NAC are used as synthetic compounds, and ascorbate, $\alpha$-tocopherol, curcumin, EGCG and EC are used as dietary elements. Here we evaluated whether the elevation of intracellular ROS and activation of MAPK attribute to selenite-induced apoptosis in Chang liver cells. To examine the role of ROS in seleniteinduced apoptosis, the effects of antioxidants on the action of selenite was first eamined. GSH, NAC, ascorbate, a-tocopherol, curcumin, EGCG and EC were treated with selenite. The working concentrations of each of antioxidants were screened in various concentrations, and then non-toxic active concentration was selected to represent the experiments (unpublished data). NAC is a precursor of GSH which is a ubiquitous tripeptide composed of glutamate, cysteine and glycine. GSH neutralizes and scavenges oxygen and other free radical species. GSH reacts with hydrogen peroxide to produce water by glutathione peroxidases and protects the cells against oxidative damage. Curcumin, diferuloyl methane, is the yellow pigment extracted from turmeric, which is commonly used as a spice and a coloring reagent especially in curries. Curcumin is known to inhibit the lipid peroxidation as an antioxidant, oxidative DNA damage, the activities of lipoxygenases and cyclooxygenases (Subramanian et al., 1994; Ruby et al., 1995). Other reports demonstrated that curcumin inhibited AP-1 function and JNK activation (Shin et al., 2001). Das and Das (2002) demonstrated that curcumin is a potent singlet oxygen quencher, but not able to scavenge hydroxyl radical. Ascorbate and $\alpha$-tocopherol are representative antioxidant vitamins. Ascorbate acts as a major antioxidant in cytosol by donation of one-electron or hydrogen atom, and indirectly reduce the $\alpha$-tocopheryl radical to $\alpha$-tocopherol in cell membrane (May, 1999). $\alpha$-Tocopherol acts as a scavenger of peroxyl radicals and an inhibitor of the free radical chain reaction of lipid peroxidation. This hydrophobic antioxidant is incorporated into cellular membranes and inhibits the elongation of free radical reactions (Packer et al., 
2001). During its action as a chain-breaking antioxidant, $\alpha$-tocopherol is consumed and converted to the radical form. Ascorbate donated electrons to the $\alpha$ tocopheryl radical and reduced back to $\alpha$-tocopherol. EGCG and EC are the most significant active polyphenols of green tea, and associated with antioxidant, antitumoral and antimutagenic activities (Katiyar et al., 2001). These polyphenols exert antioxidant activity by trapping the initiating and propagating peroxyl radicals (Liu et al., 2000). In our results, GSH, NAC, curcumin, EGCG and EC had protective effects on seleniteinduced cell death and ROS formation (Figure 4A). Instead, antioxidant vitamins did not show protective effects and we presumed that the action site of selenite is cytosol, whereas antioxidative vitamins are known to act as antioxidants in cytoplasm membrane against oxidative stress. The possible mechanisms of effective antioxidants, however, need to be further studied. We therefore considered the possibility that some antioxidants might inhibit the selenite-induced cell death and elevation of intracellular ROS level.

To examine whether the effective antioxidants reveal the protective roles might perturb the JNK pathway, the phosphorylation of MKK4 and JNK1 was assessed by immunoblot. The phosphorylation of MKK4 and JNK1 was reduced by GSH, NAC, curcumin, EGCG and EC. These results indicated that protective antioxidants reduced the selenite-induced apoptosis by attenuation of the JNK1 activation followed by MKK activation. In turn, blocking of JNK1 activation did not elevate the intracellular ROS, and as a result selenite-induced cell death was reduced by antioxidants. These results suggested that when selenium compounds were supplemented as chemopreventive or chemotherapeutic agent, the pro-apoptotic effect of selenite on normal cells should be a concern.

In summary, we identified that selenite, known as an anticancer agent, induced the apoptosis in nonmalignant cells and suggested a possible mechanism undergoing selenite-induced apoptosis is mediated by elevation of intracellular ROS level and JNK1 phosphorylation in Chang liver cell. The inhibition of JNK1 by DN-JNK1 and SP600125 attenuated the seleniteinduced cell death. Besides, the antioxidants such as GSH, NAC, curcumin, EGCG and EC reduced the selenite-induced apoptosis via inhibition of ROS generation and JNK1 phosphorylation. These findings support the hypothesis that JNK1 activation in Chang liver cells is involved in ROS mediated apoptosis by selenite.

\section{Acknowledgement}

We appreciate Dr. Seung Ki Lee (Seoul National University) for providing pcDNA3, pcDNA-Flag-JNK1 and pcDNA-Flag-DN-JNK1 plasmids, and Dr. Kee-Ho
Lee (Korea Institute of Radiological \& Medical Sciences) for technical support.

\section{References}

Clark LC, Combs GF Jr, Turnbull BW, Slate EH, Chalker DK, Chow J, Davis LS, Glover RA, Graham GF, Gross EG, Krongrad A, Lesher JL Jr, Park HK, Sanders BB Jr, Smith $\mathrm{CL}$, Taylor JR. Effects of selenium supplementation for cancer prevention in patients with carcinoma of the skin. A randomized controlled trial. Nutritional Prevention of Cancer Study Group. JAMA 1996;276:1957-63

Chung HS, Park SR, Choi EK, Park HJ, Griffin RJ, Song $\mathrm{CW}$, Park $H$. Role of sphingomyelin-MAPKs pathway in heat-induced apoptosis. Exp Mol Med. 2003;35:181-8

Combs GF Jr, Gray WP. Chemopreventive agents: selenium. Pharmacol Ther 1998;79:179-92

Das KC, Das CK. Curcumin (diferuloylmethane), a singlet oxygen $\left({ }^{1} \mathrm{O}_{2}\right)$ quencher. Biochem Biophys Res Commun 2002;295:62-6

Davis RJ. Signal transduction by the JNK group of MAP kinases. Cell 2000;103:239-52

El-Bayoumy K. The protective role of selenium on genetic damage and on cancer. Mutat Res 2001;475:123-39

Frost DV, Lish PM. Selenium in biology. Annu Rev Pharmacol 1975;15:259-84

Gasparian AV, Yao YJ, Lu J, Yemelyanov AY, Lyakh LA, Slaga TJ, Budunova IV. Selenium compounds inhibit I kappa B kinase (IKK) and nuclear factor-kappa B. Mol Cancer Ther 2002;1:1079-87

Ham YM, Choi JS, Chun KH, Joo SH, Lee SK. The c-Jun $\mathrm{N}$-terminal kinase 1 activity is differentially regulated by specific mechanisms during apoptosis. J Biol Chem 2003; 278:50330-7

Jang JH, Surh YJ. Beta-Amyloid induces oxidative DNA damage and cell death through activation of c-Jun $\mathrm{N}$ terminal kinase. Ann N Y Acad Sci 2002;973:228-36

Jiang C, Wang Z, Ganther H, Lu J. Distinct effects of methylseleninic acid versus selenite on apoptosis, cell cycle, and protein kinase pathways in DU145 human prostate cancer cells. Mol Cancer Ther 2002;1:1059-66

Kang SH, Song JH, Kang HK, Kang JH, Kim SJ, Kang HW, Lee YK, Park DB. Arsenic trioxide-induced apoptosis is independent of stress-responsive signaling pathways but sensitive to inhibition of inducible nitric oxide synthase in HepG2 cells. Exp Mol Med 2003;35:83-90

Katiyar SK, Afaq F, Azizuddin K, Mukhtar H. Inhibition of UVB-induced oxidative stress-mediated phosphorylation of mitogen-activated protein kinase signaling pathways in cultured human epidermal keratinocytes by green tea polyphenol (-)-epigallocatechin-3-gallate. Toxicol Appl Pharmacol 2001;176:110-7

Kim T, Jung U, Cho DY, Chung AS. Se-methylselenocysteine induces apoptosis through caspase activation in HL-60 cells. Carcinogenesis 2001;22:559-65 
Kim TS, Jeong DW, Yun BY, Kim IY. Dysfunction of rat liver mitochondria by selenite: induction of mitochondrial permeability transition through thiol-oxidation. Biochem Biophys Res Commun 2002;294:1130-7

Kyriakis JM, Avruch J. Mammalian mitogen-activated protein kinase signal transduction pathways activated by stress and inflammation. Physiol Rev 2001;81:807-69

Lee $\mathrm{K}$, Esselman WJ. Inhibition of PTPs by $\mathrm{H}_{2} \mathrm{O}_{2}$ regulates the activation of distinct MAPK pathways. Free Radic Biol Med 2002;33:1121-32

Liu Z, Ma LP, Zhou B, Yang L, Liu ZL. Antioxidative effects of green tea polyphenols on free radical initiated and photosensitized peroxidation of human low density lipoprotein. Chem Phys Lipids 2000;106:53-63

Mates JM, Sanchez-Jimenez FM. Role of reactive oxygen species in apoptosis: implications for cancer therapy. Int $\mathrm{J}$ Biochem Cell Biol 2000;32:157-70

May JM. Is ascorbic acid an antioxidant for the plasma membrane? FASEB J 1999;13:995-1006

Nango R, Terada C, Tsukamoto I. Jun N-terminal kinase activation and upregulation of $\mathrm{p} 53$ and $\mathrm{p} 21^{\mathrm{WAF} 1 / \mathrm{CIP} 1}$ in selenite-induced apoptosis of regenerating liver. Eur J Pharmacol 2003;471:1-8.

Park HS, Park E, Kim MS, Ahn K, Kim IY, Choi EJ. Selenite inhibits the C-Jun $\mathrm{N}$-terminal kinase/stress-activated protein kinase (JNK/SAPK) through a thiol redox mechanism. J Biol Chem 2000;275:2527-31

Packer L, Weber SU, Rimbach G. Molecular aspects of alpha-tocotrienol antioxidant action and cell signaling. J Nutr 2001;131:369S-73S

Rhee SG. Redox signaling: hydrogen peroxide as intracellular messenger. Exp Mol Med 1999;31;53-9

Ruby AJ, Kuttan G, Babu KD, Rajasekharan KN, Kuttan R. Anti-tumour and antioxidant activity of natural curcuminoids. Cancer Lett 1995;94:79-83

Sakon S, Xue X, Takekawa M, Sasazuki T, Okazaki T, Kojima Y, Piao JH, Yagita H, Lkumura K, Doi T, Nakano H. NF-kappa B inhibits TNS-induced accumulation of ROS that mediate prolonged MAPK activation and necrotic cell death. EMBO J 2003;22:3898-999
Sano M, Fukuda $K$, Sato $T$, Kawaguchi $H$, Suematsu $M$, Matsuda S, Koyasu S, Matsui H, Yamauchi-Takihara K, Harada M, Saito Y, Ogawa S. ERK and p38 MAPK, but not NF-kappaB, are critically involved in reactive oxygen speciesmediated induction of IL- 6 by angiotensin II in cardiac fibroblasts. Circ Res 2001;89:661-9

Shen $\mathrm{H}$, Yang $\mathrm{C}$, Liu J, Ong $\mathrm{C}$. Dual role of glutathione in selenite-induced oxidative stress and apoptosis in human hepatoma cells. Free Radical Biology and Medicine 2000; 28:1115-24

Shen H, Yang C, Ding W, Liu J, Ong C. Superoxide radical-initiated apoptotic signalling pathway in selenite-treated HepG2 cell: Mitochondria serve as the main target. Free Radical Biology and Medicine 2001;30:9-21

Shin EY, Kim SY, Kim EG. c-Jun N-terminal kinase is involved in motility of endothelial cell. Exp Mol Med 2001;33: 276-83

Shtil AA., Mandlekar S, Yu R, Walter RJ, Hagen K, Tan TH, Roninson IB, Kong AN. Differential regulation of mitogenactivated protein kinases by microtubule-binding agents in human breast cancer cells. Oncogene 1999;18:377-84

Stadtman TC. Biosynthesis and function of selenocysteinecontaining enzymes. J Biol Chem 1991;266:16257-60

Subramanian M, Sreejayan, Rao MN, Devasagayam TP, Singh BB. Diminution of singlet oxygen-induced DNA damage by curcumin and related antioxidants. Mutat Res 1994; 311:249-55

Yoon SO, Kim MM, Park SJ, Kim D, Chung J, Chung AS. Selenite suppresses hydrogen peroxide-induced cell apoptosis through inhibition of ASK1/JNK and activation of PI3K/Akt pathways. FASEB J 2002;16:111-3

Yu R, Shtil A, Tan T-H, Roninson IB, Kong AN. Adriamycin activates c-Jun $\mathrm{N}$-terminal kinase in human leukemic cells: a relevance to apoptosis. Cancer Lett 1996;107:73-81

Zeng $\mathrm{H}$. Arsenic suppresses necrosis induced by selenite in human leukemia HL-60 cells. Biol Trace Elem Res 2001; 83:1-15

Zhu $\mathrm{Y}, \mathrm{Xu} \mathrm{H}$, Huang $\mathrm{K}$. Mitochondrial permeability transition and cytochrome $\mathrm{C}$ release induced by selenite. J Inorg Biochem 2002;90:43-50 